\title{
UN MAL CASO PARA FLEXIBILIZAR LA TIPICIDAD EN EL DERECHO ADMINISTRATIVO SANCIONADOR. COMENTARIO AL FALLO "EMPRESA DE SERVICIOS SANITARIOS ESSBIO S.A. CON SEREMI DE SALUD DEL BIOBÍO” DE LA CORTE SUPREMA, ROL No 7397-2012
}

\author{
A BAD CASE FOR FLEXIBILIZE THE TYPOLOGY OF ADMINISTRATIVE \\ SANCTIONS. \\ COMMENTARY TO CASE "EMPRESA DE SERVICIOS SANITARIOS \\ ESSBIO S.A. V. SEREMI DE SALUD DEL BIOBIO" OF THE SUPREME \\ COURT, ROL NO. 7397-2012
}

\section{Pablo Soto Delgado*}

\begin{abstract}
RESUMEN: Eltexto analiza la posibilidad de que el Derecho Administrativo sancionador opere dentro de un esquema flexible. Si bien el legislador se encuentra autorizado para ello, la Administración no puede desvincularse de la explícita programación que aquel ha establecido al definir las conductas a sancionar. La Corte Suprema, en el fallo que se comenta, ha permitido la imposición de multas a un particular basándose en la contravención de disposiciones que solo otorgan competencia al órgano administrativo, con lo cual, se difumina la tipicidad y consecuentemente, la posibilidad de que el administrado pueda conducirse conforme a derecho.
\end{abstract}

Palabras clave: Sanciones administrativas, tipicidad, control judicial de la Administración.

ABSTRACT: The text analyzes the possibility that administrative sanctions operates within a flexible scheme. Though the legislator is authorized for it, the Administration cannot disobey the explicit statutory program that defined the conducts to be sanctioned. The Supreme Court, in the case that is commented, has authorized the imposition of fines basing in the breach of regulations that only grant competence to the administrative agency. As a consequence of the foregoing the typology of administrative offences fades away and with it the possibility to behave in conformity with law.

Key words: Administrative sanctions, typology of offences, judicial review of the Administration.

\section{INTRODUCCIÓN}

La postura dominante en la doctrina y jurisprudencia ${ }^{1}$-administrativa, judicial y constitucional- chilena considera que el Derecho Administrativo sancionador y el Derecho Penal son dos manifestaciones del supraconcepto ius puniendi ${ }^{2}$, en el que se articulan todas

\footnotetext{
Abogado. Profesor de Derecho Administrativo y doctorando en Derecho, Facultad de Derecho, Universidad Diego Portales. Dirección postal: República 112, Santiago, Chile. Código postal: 8370074 . Correo electrónico: pablo.soto@mail.udp.cl.

1 Una acabada exposición en Cordero y Aldunate (2012).

2 Acerca del ius puniendi como supraconcepto, NieTo (2012) p. 124.
} 
las potestades represivas del Estado. Siguiendo la vertiente española sobre la materia, desarrollada a fines de los años 70 y luego afirmada por el Tribunal Constitucional español ${ }^{3}$, se ha asentado entre nosotros la idea de que el pretendido origen común implica que los principios de la rama penal deben transferirse a la administrativa, aun prescindiendo del preciso lenguaje referido a asuntos criminales que la Constitución de 1980 utiliza ${ }^{4}$. Hay quienes consideran inapropiada esta forma de limitar las potestades sancionatorias de la Administración puesto que pone trabas excesivas al ejercicio de las funciones públicas encomendadas a los órganos de la Administración del Estado5. Como certeramente se ha señalado, a diferencia del Derecho Penal, el Derecho Administrativo no es puro garantismo individual, sino que también ha de asegurar los intereses de la comunidad ${ }^{6}$.

Ahora bien, la comunicación de los principios desde un subsector a otro debe efectuarse -se afirma- bajo una modalidad específica: con "matices". Esta es la tesis que el Tribunal Constitucional (TC) consistentemente ha sostenido desde la sentencia relativa a la Ley de Caza ${ }^{7}$. Allí, el TC indicó que, "por regla general"8, los principios penales son aplicables al Derecho Administrativo sancionador, relativizando, por tanto, el traspaso desde un ámbito regulatorio al otro. Esta posición no ha ensayado una formulación general acerca de los "matices", cuestión que ha sido criticada desde autores partidarios de la aplicación de los principios penales, pues, generaría incertidumbre para el administrado?

Una manera de comprender los matices se encuentra en la flexibilización del contenido de los principios, lo cual significa admitir menores exigencias para el ámbito de las sanciones administrativas en comparación con el Derecho Penal. Esta es la idea contenida en el fallo de la Corte Suprema (CS), que se comenta en lo que sigue (caso ESSBIO) ${ }^{10}$. Esa tesis, sin embargo, requiere un contenido y unos supuestos claros de aplicación, de lo contrario, solo avala la ilegalidad. Precisamente, la sentencia de que se trata, acaba validando la imposición de multas por la Secretaría Regional Ministerial de Salud del Biobío (SEREMI) en contra de la empresa de servicios sanitarios por incumplir una disposición que solo atribuye

\footnotetext{
3 Huergo (2007) p. 20. Es clave en la construcción de esta idea el artículo de García de Enterría (1976) y algunos fallos del Tribunal Constitucional español. PAREjo (2008) p. 649, afirma que esta tesis originalmente proviene desde la jurisprudencia contencioso administrativa de comienzo de los años 70 .

${ }^{4}$ El considerando $11^{\circ}$ del voto de minoría del ministro Jorge Correa en la resolución de los requerimientos de inaplicabilidad ante el Tribunal Constitucional, roles No 479 y 480 de 2006, es la expresión más clara de la postura según la cual no existen argumentos dogmáticos ni históricos asociados al establecimiento del artículo 19 No 3 de la Constitución que otorguen solvencia a la unidad entre el Derecho Administrativo Sancionador y el Derecho Penal, y que, en consecuencia, los principios de este último no deben traspasarse a aquel: "Para jueces constitucionales no es un hecho menor anotar que en el caso español, a diferencia del chileno existe un precepto en la Carta Fundamental que sujeta a toda sanción y no solo a las penas al principio de legalidad (artículo 25.1 del texto constitucional español). La asimilación en ese país resulta entonces obligada por el texto constitucional que la legitima”.

5 Самасно (2006) pp. 18-19.

6 Vallejo y Guiloff (2014) p. 6.

7 Rol No 244, de 26 de agosto de 1996.

8 Considerando $9^{\circ}$.

9 Verdugo y García (2011) pp. 12-13.

10 Rol No 7397-2012, de 16 de septiembre de 2013.
} 
competencia al servicio, sin establecer un supuesto de conducta susceptible de ser infringido por el administrado.

El presente comentario de jurisprudencia pretende evaluar las razones sostenidas por la CS al resolver el caso ESSBIO, proponiendo, además, una lectura de la flexibilidad como modo de enfrentar la matización en la transferencia de los principios penales al aplicar sanciones administrativas. Para ello será necesario referirse al modo en que puede operar la flexibilidad del administrador al relacionarse con la ley (1). Enseguida, se expondrá el caso, revisándose las argumentaciones de la Corte de Apelaciones (CA) de Concepción y de la CS (2). Finalmente, se analizarán críticamente las consideraciones jurídicas que sustentan el fallo de esta última (3).

\section{MATICES EN LA APLICACIÓN: FLEXIBILIDAD Y TRANSITIVIDAD}

Un aspecto clave de la estructura estatal moderna se encuentra en que la preferencia interpretativa de la ley se confiere a la Administración del Estado, y que, en tal calidad, debe lograr que los propósitos legislativos se realicen ${ }^{11}$. De ahí que ya no pueda entenderse que el actuar de la Administración consista en aplicar el derecho bajo la modalidad de mera ejecución mecánica, como lo pretende un modelo administrativo tradicional originado en el Estado liberal de Derecho, que descansa en clásicas ideas, tales como: la división de poderes; la dirección de la Administración a través de leyes con el mayor grado de detalle posible para cada supuesto; y el control judicial bajo la premisa de que solo hay una decisión correcta, por lo cual, los tribunales tienen siempre la última palabra y podrán sustituir la decisión administrativa ${ }^{12}$. Esta perspectiva tradicional ha generado una específica comprensión de la legalidad, conforme a la cual, la tipificación normativa se encuentra en la ley; el tipo se subdivide en presupuestos de hechos y consecuencia jurídica; y la aplicación del tipo normativo se lleva a cabo a través de un método escalonado de tres fases: interpretación, identificación del supuesto de hecho y subsunción ${ }^{13}$.

Pero el Derecho Administrativo moderno, en diversos ámbitos, funciona de otra manera. Ya no se trata siempre de una mera reproducción de lo que la ley haya dispuesto. "[E]llo porque el legislador puede confiarle al aplicador del Derecho la responsabilidad de que lleve a cabo una compleja y difícil ponderación de los intereses, bienes y valores en presencia para el caso concreto; o transferirle «momentos decisorios» de suma relevancia. [...] En este contexto, por tanto, no cabe excluir que el legislador pueda hacer uso de conceptos o criterios como, por ejemplo, la eficiencia económica, que la Administración ha de gestionar" ${ }^{\prime 4}$. Esto trae consecuencias para el Derecho Administrativo, que ha de articularse en términos responsivos ${ }^{15}$, lo cual significa que debe tener la capacidad de adaptarse selectivamente a su entorno, proporcionando a la Administración herramientas que habiliten y

\footnotetext{
11 Rubin (2007) p. 64.

12 Schmidt-Assmann (2012) p. 35.

13 Schmidt-Assmann (2012) p. 97.

14 Schmidt-Assmann (2012) p. 101.

15 Nonet y Selznick (2009) p. 77. Para la aplicación de esta perspectiva al Derecho Administrativo en Chile, Montt (2010).
} 
faciliten que el cumplimiento de los propósitos públicos ${ }^{16}$, fijados por el legislador democrático. La incorporación de esas finalidades, importa introducir en la aplicación del derecho estándares de apertura y flexibilidad ${ }^{17}$.

Sin embargo, no toda la actividad de la Administración se encuentra configurada normativamente del modo señalado. En efecto, pueden identificarse situaciones en que las disposiciones no determinan las reglas que aquella deberá hacer operativas. Esto es consecuencia de un atributo de la ley, denominado grado de transitividad $^{18}$, conforme al cual es posible evaluar su intensidad regulatoria. En una escala hipotética pueden hallarse dos extremos: transitividad si una disposición señala con precisión la regla que un órgano debe aplicar, e intransitividad si no. Figurativamente, la transitividad es una señal proveniente desde el legislador, transmitida al órgano administrador sin que este la intervenga para aplicarla a los sujetos imperados. En virtud de la intransitividad, en cambio, la señal es recibida por la Administración que, luego de sucesivas acciones, la transforma en una nueva señal dirigida al administrado, permitiendo a los órganos administrativos desarrollar nueva regulación, con tal que cumpla con los objetivos de una determinada política pública. Solo en este contexto intransitivo adquiere sentido una comprensión de la legalidad como flexibilidad, puesto que son las técnicas del legislador aquellas que lo han posibilitado (i) dirigiendo la Administración mediante conceptos legales y presupuestos de hecho abiertos; (ii) estableciendo cláusulas y mandatos de ponderación entre bienes y valores; (iii) señalando fines y garantías de resultado; y (iv) otorgando habilitaciones legales para que la Administración disponga de márgenes de apreciación y de valoración, como ocurre en el Derecho ambiental y de la seguridad técnica ${ }^{19}$. En tales supuestos, es un enfoque obligado que la flexibilidad sea el método para interpretar la ley.

Lo que tenemos, entonces, son dos posiciones frente a la ley: flexibilidad para aproximarse a la legalidad cuando el legislador genera las condiciones para ello, y legalidad en sentido clásico cuando no ${ }^{20}$. Las sanciones administrativas pueden operar en ambas modalidades y el legislador se encuentra habilitado para dotar a los órganos reguladores de un espacio que no rigidice su actuación ${ }^{21}$; incluso puede llegar a ser aconsejable un esquema regulatorio flexible, bajo ciertas condiciones que promuevan la cooperación del adminis$\operatorname{trado}^{22}$. Ahora bien, cuando esto no sucede, es decir, si la ley no ha transferido momentos decisorios flexibles a la Administración, la legalidad obliga al aplicador a interpretar, verificar hechos y subsumir. En el caso que en seguida se expone, la SEREMI primero, y la

\footnotetext{
16 Nonet y Selznick (2009) p. 111.

17 Nonet y Selznick (2009) p. 80.

18 Rubin (2007) p. 210. En el caso chileno, Guiloff (2012) ha explicado la relación entre la ley y la potestad reglamentaria basándose en la tesis gradual de transitividad de Rubin.

19 Schmidt-Assmann (2012) p. 98.

20 Esto significa que no todos los ámbitos de referencia en el Derecho Administrativo operan de la misma manera, lo cual obedece a que los diversos sectores pueden encontrarse configurados por diversos modelos normativos. Sobre el punto, véase SchmidT-Assmann (2003) p. 12.

21 Sobre el principio de legalidad en materia administrativa sancionatoria como estándar distinto al del Derecho Penal, véase Londoño (2014).

22 Ayres y Braithwaite (1992) p. 34.
} 
Corte Suprema en sede de casación, luego, utilizaron la metodología contraria: a pesar de encontrarse programado por el legislador de modo preciso cuál era la conducta susceptible de sancionarse, se flexibilizó la legalidad.

\section{EL CASO ESSBIO}

\section{1. $\mathrm{HeCHOS}^{23}$}

(i) La Secretaría Regional Ministerial de Salud del Biobío sancionó, a través de la Resolución Exenta N ${ }^{\circ} 11.113^{24}$, de 10 de septiembre de 2009, a la Empresa de Servicios Sanitarios del Biobío S.A. (ESSBIO S.A.), imponiéndole una multa de 200 UTM, por infracción a los artículos 67 y 73 del Código Sanitario.

(ii) Los hechos descritos en el acto administrativo sancionador consisten en la comprobación, durante la investigación sanitaria, del vertido, por parte de contratistas que prestaban servicios a ESSBIO S.A., de tierra y aguas contaminadas con materia fecal en un canal de captación de aguas lluvia. El material fue extraído desde una cámara de alcantarillado previamente destapada por los contratistas, situada a no más de diez metros en el Pasaje Mariano Latorre, Población Nueva La Greda, Penco, lo que genera foco de insalubridad y daños a la salud de las personas.

(iii) Como antecedente para la determinación de la infracción, se indicó en la referida resolución la denuncia de un particular referida al destape y depósito del material, así como la visita inspectiva que el 24 de septiembre de 2008 efectuaron funcionarios de la oficina Talcahuano del órgano administrativo, quienes verificaron el vertido de tierras y aguas contaminadas con materia fecal en un canal de captación de aguas lluvia, a no más de diez metros de la cámara desde donde se habrían retirado dichos elementos.

(iv) En contra de la resolución de la SEREMI, la empresa presentó un reclamo, conforme al artículo 171 del Código Sanitario ${ }^{25}$, ante el 2o Juzgado Civil de Concepción, que fue desestimado por extemporáneo.

23 Para esta reconstrucción, se ha tenido a la vista, además de las sentencias del 2o Juzgado Civil de Concepción, Rol N³132-2010, de 5 de octubre de 2011 y de la CA de Concepción, Rol N86-2012, de 28 de agosto de 2012, (i) el acta de inspección $N^{\circ} 4096$ de 24 de septiembre de 2008 que dio inicio al referido sumario, (ii) la Resolución sanitaria $N^{\circ} 11.113$ de 10 de septiembre de 2009; (iii) la Resolución $N^{\circ} 1.301$, de 19 de mayo de 2010 que confirma la resolución sanitaria $\mathrm{N}^{\circ} 11.113$ de 10 de septiembre de 2009. Los antecedentes administrativos fueron proporcionados por el SEREMI de Salud del Biobío, mediante Oficio Ordinario No 3250 de fecha 15 de octubre de 2014, previa solicitud de acceso a la información.

24 Acto administrativo denominado "sentencia", de acuerdo a los artículos 167, 168, 170, 171, 172 y 181 del Código Sanitario.

25 El inciso primero de ese artículo dispone: "De las sanciones aplicadas por el Servicio Nacional de Salud podrá reclamarse ante la justicia ordinaria civil, dentro de los cinco días hábiles siguientes a la notificación de la sentencia, reclamo que tramitará en forma breve y sumaria”. 


\subsection{La Corte de Apelaciones de Concepción ${ }^{26}$}

En apelación, sin embargo, la CA de Concepción descartó la extemporaneidad resuelta en primera instancia, dando por acreditado que la empresa reclamante, efectivamente, llevó a cabo la conducta reprochada:

"Por consiguiente, en virtud de los antecedentes y razonamientos expuestos, debe darse por establecido que la empresa reclamante vertió en el canal de desagüe material fecal y aguas servidas extraídas desde la cámara de alcantarillado ubicada a unos diez metros de ese sitio" 27.

A pesar de lo anterior, la CA dejó sin efecto la resolución sancionatoria, analizando las disposiciones legales que en la sentencia administrativa se citaban como fundamento para la multa, a saber, los artículos 67 y 73 del Código Sanitario. Así, distingue entre ambas, afirmando que mientras la primera es una norma que atribuye una competencia, la segunda contiene un tipo infraccional. Afirma la Corte:

"Que examinando lo dispuesto en los artículos 67 y 73 del Código Sanitario, esgrimidos como fundamento legal de la infracción atribuida a la empresa reclamante, se puede constatar que el primero es una norma de competencia de los Servicios de Salud, pues prescribe que les corresponde "velar porque se eliminen o controlen todos los factores, elementos o agentes del medio ambiente que afecten la salud, la seguridad y el bienestar de los habitantes en conformidad a las disposiciones del presente Código y sus reglamentos".

En cambio, el segundo precepto consagra ciertamente una figura infraccional al establecer que se prohíbe "descargar las aguas servidas y los residuos industriales o mineros en rios o lagunas, o en cualquier otra fuente o masa de agua que sirva para proporcionar agua potable a alguna población, para riego o para balneario, sin que antes se proceda a su depuración en la forma que se señale en los reglamentos" ${ }^{28}$.

Confrontando esta última regla -el artículo 73 del Código Sanitario- con la conducta de ESSBIO S.A., la CA considera que esta no se encuentra cubierta por la hipótesis típica, puesto que lo que la disposición "prohíbe es la descarga de aguas contaminadas en cualquiera masa o fuente de agua destinada a proporcionar agua potable para el consumo de la población, para riego o para balneario, destinación que claramente la captación en que fueron depositadas las materias contaminadas o contaminantes no tiene, pues su objetivo es canalizar o servir de desagüe de las aguas lluvia, como la propia resolución de multa lo reconoce" 29 . La CA de Concepción funda su razonamiento en una concepción de legalidad clásica, conforme a la cual, falla la tipicidad respecto al artículo 73. Este es, pues, un caso en que "los

\footnotetext{
${ }^{26}$ CA de Concepción, Rol No 86-2012, de 28 de agosto de 2012.

27 Considerando $7^{\circ}$.

28 Considerando $8^{\circ}$. Las cursivas son del original.

29 Considerando 8). El destacado es nuestro.
} 
hechos que la sentencia administrativa dio por acreditados no concuerdan con la descripción de aquellos que la norma legal pretende castigar con algunas de las sanciones[del Código Sanitario]"30.

\subsection{El razonamiento de la Corte Suprema ${ }^{31}$}

En contra del fallo de la CA de Concepción la SEREMI presentó un recurso de casación de fondo ${ }^{32}$. Aquí es relevante tomar en consideración dos argumentos de la recurrente, a saber:

(i) Que existe un vicio cuando la CA de Concepción exige que la resolución sancionatoria deba necesariamente citar la norma infringida, puesto que bastaría con indicar de modo preciso y exacto los hechos constitutivos de infracción, en tanto, en el derecho administrativo sancionatorio no se exige el grado de tipicidad dable en el orden del derecho penal. El procedimiento administrativo sancionador "no está directamente vinculado con determinada disposición de ley en la que se describa una conducta antijurídica y se señale para ella un castigo; basta que gire en torno a deberes y obligaciones de los administrados, supuestamente incumplidos".

(ii) Que, de acuerdo al artículo 20 del Código Penal, no se reputan penas las multas ni demás correcciones que la autoridad impone a los administrados en uso de su jurisdicción disciplinaria. De ahí que la exigencia constitucional en este caso solo se refiera al derecho a la defensa, lo que fue totalmente respetado, como queda claro en el fallo de la CA.

La CS considera que el punto central del caso está en la "tipicidad en el ámbito del derecho administrativo" 33 , principio relacionado con la predeterminación normativa, y conforme al cual, "por el solo hecho de formar parte de la comunidad organizada, toda persona debe conocer de antemano las conductas que el ordenamiento prohíbe, así como las consecuencias que su transgresión conlleva" ${ }^{4}$. La tesis del fallo es que el principio de tipicidad debe flexibilizarse al aplicarse sanciones administrativas. Para ello, formula los siguientes argumentos:

1. Es necesario atender a las funciones y deberes que el ordenamiento jurídico impone al Estado, y a los instrumentos para llevar a cabo su labor, lo que tiñe de "servicia-

30 Considerando $9^{\circ}$.

31 Rol No 7397-2012, de 16 de septiembre de 2013. La redacción del fallo estuvo a cargo del entonces ministro Suplente Carlos Cerda.

32 Señalando que se habrían infringido los artículos 67, 73, 166 y 171 del Código Sanitario; 20 del Código Penal; y 19 y 22 del Código Civil. Se ha tenido a la vista el escrito mediante el cual se interpone el recurso de casación en el fondo, presentado por la Procuraduría Fiscal del Consejo de Defensa del Estado de la ciudad de Concepción.

33 Considerando $4^{\circ}$.

34 Considerando $4^{\circ}$. 
lidad" el vínculo con el ciudadano, cuestión que importa promover el bien común, de acuerdo al artículo $1^{\circ}$ de la Constitución ${ }^{35}$.

2. La salud pública, la sanidad y la no contaminación han sido incorporados al ordenamiento como bienes jurídicos con un "especial régimen protectivo (sic)"36.

3. Hay dos modalidades de reprimir la lesión de dichos bienes: la penal y la administrativa. Por ambas, el Estado puede corregir y sancionar. Ahora bien, a diferencia de la pena penal, que, a juicio de la Corte, es necesariamente aflictiva o represiva, y opera como consecuencia determinada de un ilícito criminalmente punible, la sanción administrativa tiene una lógica diversa: "En este ámbito, se está también en presencia de un ilícito y de una potestad represiva, pero sucedánea a una inconducta que no se encuentra criminalmente descrita, sino a una contravención a reglas de ordenación y convivencia, ajenas a la experiencia jurídico-criminógena" ${ }^{37}$.

4. Con lo anterior en consideración, la CS afirma que el punto clave en el ámbito de las sanciones administrativas está en que basta allí con verificar la conducta y un atentado a las reglas de convivencia aludidas, que están "destinadas a posibilitar a la Administración el eficaz servicio a que está llamada”, lo cual contrasta con una "precisa, ajustada y explícita denominación del precepto sobre la base del cual se reprime" 38 . Se sigue de aquí -concluye la Corte- "una suerte de flexibilización del rigor del principio de tipicidad en el orden de materias aquí convocantes"39.

Bajo esta idea flexibilizada de la tipicidad, la CS analiza el fallo de la CA de Concepción. Para ello, revisa la disposición citada por la SEREMI como fundamento de la sanción (el artículo 67 del Código Sanitario), señalando que allí se fija el deber de servicio público que "hace irrenunciable el cumplimiento de sus tareas" ${ }^{40}$. Agrega la Corte que "[i]nnúmeras otras disposiciones del Código Sanitario apuntan al servicio inherente al resguardo de la salubridad pública” ${ }^{41}$.

Enseguida, explica la CS que en sede de casación de fondo ha de otorgarse eficacia al derecho, sin que sea posible, conforme al axioma iuranovit curia, "dejar en el desamparo a determinada situación, so pretexto de un supuesto yerro en la correspondiente invocación normativa, al consumarse la potestad sancionadora” ${ }^{42}$.

Finalmente, explica la Corte de qué modo la flexibilización de la tipicidad impacta en el razonamiento jurídico en el ámbito sancionatorio administrativo:

\footnotetext{
Considerando $5^{\circ}$.

Considerando $6^{\circ}$.

Considerando $7^{\circ}$. El destacado es nuestro.

Considerando $9^{\circ}$.

Considerando $10^{\circ}$. El destacado es nuestro.

Considerando $12^{\circ}$.

11 Considerando $13^{\circ}$.

42 Considerando $14^{\circ}$.
} 
"la ductilidad del principio de legalidad de cara a la aplicación de la tipicidad en contextos diversos al del derecho penal, no solo contagia la perspectiva deductiva en la que de ordinario discurre el esfuerzo jurisdiccional criminalístico, sino y sobre todo, la mira inductiva.

No se trata ya tanto de un esfuerzo por comprobar si en la realidad enjuiciada se cuenta con los elementos del precepto castigador -deducción- sino, más propiamente, de hurgar en el espectro normativo cuál sea el modo que se advierte mayormente legítimo para sancionar una conducta claramente prohibida -inducción-.

La diferencia salta a la vista: la piedra angular se desplaza desde la disposición represora hacia el quehacer infractor.

Aquí la labor del derecho impele a la jurisdicción a "hallarse" con el mandato del ordenamiento que blinde eficazmente la legitimidad de la prestación del servicio público" ${ }^{33}$;

La CS considera que la CA de Concepción, que dejó sin efecto lo obrado por la autoridad sanitaria por un vicio de tipificación jurídica, no actuó correctamente y casa el fallo de segunda instancia, no sin antes señalar que los jueces de alzada "dejaron impune un comportamiento que, tal como está inamoviblemente sentado, se enmarca en lo que el mentado 67 veda" ${ }^{44}$. Concluye, en definitiva, que:

"Es por ello que comparecen todas y cada una de las hipótesis que [el] inciso segundo [del artículo 171 del Código Sanitario ${ }^{45}$ ] prevé para el rechazo de la reclamación, a saber, los hechos se encuentran comprobados en el sumario sanitario, constituyen efectivamente una infracción al ordenamiento y, por último, la multa está concedida como castigo ante ello" ${ }^{46}$;

\section{ANÁLISIS CRÍTICO}

El fallo de la CS tiene defectos que ponen en cuestión su calidad argumentativa. Como se apreciará, es inapropiada la manera en que resuelve la anulación de la sentencia de la CA de Concepción, fundándose en que la vinculación entre la Administración y la ley, en el caso de las sanciones administrativas, es débil. La sentencia del caso ESSBIO, además, expresa un modo de razonamiento que omite controlar jurídicamente el acto de aplicación de la ley por parte de la Administración.

43 Considerando $15^{\circ}$.

44 Considerando $15^{\circ}$

45 Ese inciso dispone: "El tribunal desechará la reclamación si los hechos que hayan motivado la sanción se encuentren comprobados en el sumario sanitario de acuerdo a las normas del presente Código, si tales hechos constituyen efectivamente una infracción a las leyes o reglamentos sanitarios y si la sanción aplicada es la que corresponde a la infracción cometida”.

46 Considerando $16^{\circ}$. El destacado es nuestro. 


\subsection{FleXibILIDAD NO AUTORIZADA}

La sentencia en análisis determina que en la aplicación de sanciones administrativas, la Administración se encuentra débilmente vinculada a la ley. Esta lectura de las potestades sancionadoras no se encuentra autorizada por el ordenamiento. Como se señaló en la primera parte de este comentario, los supuestos en los que resulta adecuada una metodología interpretativa que otorgue a los órganos administrativos una flexibilidad o apertura para cumplir los fines públicos, deben establecerse por el legislador. No es lo que acontece en la especie, donde, como la CA de Concepción correctamente decidió, la infracción se encontraba taxativamente fijada. El artículo 73 del Código Sanitario - una de las disposiciones que fundaron la multa a ESSBIO S.A.- establece una hipótesis infraccional clara, conforme a la cual se prohíbe descargar aguas servidas y residuos industriales o mineros en ríos o lagunas, o en cualquiera otra fuente o masa de agua que sirva para proporcionar agua potable a alguna población, para riego o para balneario, sin depurarla previamente. Esta regla es de un tipo característicamente transitivo, es decir, regula de manera precisa cómo debe conducirse la Administración ${ }^{47}$.

La Corte Suprema, entonces, al anular la sentencia de la CA de Concepción, efectúa una operación argumentativa conforme a la cual transforma en intransitiva una norma que no puede serlo; por el contrario, en este caso, la vinculación entre la Administración y la ley que aplica es de tipo fuerte. Con ello, valida que la SEREMI se conduzca de esa manera. Pero no solo eso, pues, la intransitividad que la CS autoriza, permite a la Administración desplazarse, para fundar la sanción, desde la disposición que expresamente establece la conducta infraccional, hacia otra que solo indica bienes que el ordenamiento busca proteger, sin que constituyan deberes para el administrado: el artículo 67 del Código Sanitario. Este otorgamiento de flexibilidad a la Administración cuando no se encuentra autorizada es, sin más, una ilegalidad.

\subsection{EL EMPEORAMIENTO DE LA LEGALIDAD ORDINARIA}

La CS fija el estándar de control de la legalidad en materia administrativa sancionatoria en un nivel más bajo que el exigible en el tráfico común de la actividad de la Administración del Estado. Si bien puede ser discutible que en materia sancionatoria la legalidad deba tener un contenido más rígido que en otros ámbitos, no parece problemático que debieron respetarse aquí, como en cualquier supuesto de actuación administrativa, los requisitos del acto administrativo (subjetivos, objetivos y formales ${ }^{48}$ ). Esto es lo que en definitiva exigía evaluar el contencioso del artículo 171 del Código Sanitario. En el aspecto subjetivo, la competencia del órgano que dictó el acto administrativo sancionatorio es un elemento que quedaba bajo el control judicial. Sobre este punto, es necesario señalar que la tipificación de la infracción es un supuesto concreto que define el ámbito en que el órgano puede ejercer su potestad sancionatoria. Fuera de él, no puede hacerlo. Esto significa que en este caso la SEREMI carecía de competencia para aplicar la sanción administrativa. La

\footnotetext{
47 Resulta tan claro que el artículo 73 no cubría la hipótesis, que la Corte tuvo que acudir a diversas normas del Código Sanitario que establecen bienes generalmente tutelados para considerarlas infringidas.

48 García de Enterría y Fernández (2011) pp. 575 y ss.
} 
Corte, sin embargo, no efectuó un control jurídico, conforme al cual debieron evaluarse si los términos de la ley definían el ámbito de actuación de la autoridad ${ }^{49}$.

A cambio de un control estricto de derecho, la CS creó un principio de legalidad deductivo, que permite sancionar cualquier conducta que se considere reprochable, aun cuando el legislador no lo hubiese establecido de ese modo, en la medida que pueda reconducirse a cualquier bien protegido por el Código Sanitario ${ }^{50}$. Esto es especialmente claro cuando, como se señaló, el artículo 67 de dicho código es un precepto cuyo destinatario es la autoridad sanitaria y no el administrado. La consecuencia de ello es que no existe diferencia entre aplicar sanciones con una norma preexistente o hacerlo sin ella, admitiéndose, entonces, la creación de infracciones en misma sentencia administrativa que pone término al sumario sanitario y que aplica la sanción ${ }^{51}$.

\subsection{LA CONFUSIÓN ENTRE FUNDAMENTACIÓN Y APLICACIÓN DE NORMAS}

En su sentencia, la CS confunde los niveles de discurso jurídico en que debe operar. A este respecto, es posible distinguir entre casos en los que el operador se encuentra autorizado para proporcionar razones acerca de la aplicación de normas jurídicas, por una parte; y por otra, casos en los que el ordenamiento permite que las razones que el operador entrega, sean para la fundamentación de normas ${ }^{52}$. El legislador es un operador que puede fundamentar la existencia de normas. El Poder Judicial, en cambio, solo puede emitir discursos de aplicación en sus fallos ${ }^{53}$, a través de un proceso interpretativo que entrelace la descripción de los hechos con la norma general, verificando "la equivalencia semántica entre la descripción del estado de cosas [...] y la descripción del estado de cosas que viene establecido en el componente descriptivo de la norma, es decir, en la condición de su aplicación" ${ }^{54}$. En este caso no queda duda de que la CS, al efectuar el control del acto administrativo sancionatorio, solo puede proveer razones acerca de si la ley fue correctamente aplicada por el SEREMI y le está vedada la introducción de argumentos dirigidos a producir -fundamentar- nuevas obligaciones que el legislador no ha contemplado. Lo anterior es especialmente sensible cuando, como sucede en el caso ESSBIO, la configuración del ámbito de referencia

49 Este es el paradigma de control jurisdiccional tratándose de cuestiones de derecho, que deben diferenciarse del control en torno a cuestiones discrecionales. Al respecto, Craig (2007) p. 2.

50 Un antecedente de este modo de razonar, se encuentra en una sentencia de la Corte Suprema de fecha 29 de julio de 2011, Rol No 5.779-2009, redactada por el ministro Pedro Pierry. Allí, se sostuvo que es conforme a derecho una sanción administrativa fundada en la infracción de una norma que solo alude a bienes que la legislación busca proteger, estableciendo un reenvío a la potestad reglamentaria. En su considerando $5^{\circ}$ señala ese fallo que " $[\mathrm{e}] \mathrm{n}$ este escenario [del Derecho Administrativo sancionador], para dilucidar si la conducta es merecedora de reproche, debe estarse al interés o bien jurídico que se pretende proteger en la legislación y si este se ha visto amagado por la actuación del actor".

51 Vulnerándose la prohibición de retroactividad de los actos administrativos de efecto desfavorable, contenida en el artículo 52 de la Ley No 19.880 .

52 Habermas (2001) p. 287, siguiendo a Klaus Günther.

53 Salvo que exista una laguna que deba ser colmada. En tal circunstancia, el juez debe señalar la existencia de ese vacío, cuestión que no aconteció en el presente caso.

54 Habermas (2001) p. 289. El Tribunal Constitucional, al efectuar controles abstractos de constitucionalidad también se encuentra autorizado para emitir discursos de fundamentación en la medida que puede cuestionar las razones que el legislador tuvo en consideración para dictar una ley. 
de las sanciones administrativas opera con un tipo específico de normas, denominadas "reglas", esto es, bajo el esquema de todo o nada, conforme al cual si los hechos que en ellas se establecen se dan por acreditados, la consecuencia se sigue necesariamente. De lo contrario, las reglas nada aportan a la decisión ${ }^{55}$. Como se ha señalado, la regla del artículo 67 del Código Sanitario no contenía ninguna hipótesis para este caso, de ahí que nunca pudo ser aplicada. Pero la Corte decidió sustituir al legislador y creó una nueva infracción sobre la base de razones funcionalistas que solo estaban a disposición de quien debe fundamentar la existencia de normas.

La operación argumentativa de la CS va incluso más allá de cualquier competencia de control de constitucionalidad atribuida al TC. En efecto, este último órgano solo se encarga de descartar sobre la base de razones constitucionales que una disposición pueda convertirse en ley o bien sea aplicada al caso. La CS, por el contrario, también sobre la base de razones constitucionales (principio de servicialidad contenido en el artículo $1^{\circ}$ de la Constitución o el Estado de Derecho como Estado de Justicia ${ }^{56}$ ), se encargó de crear una nueva hipótesis no contemplada por el legislador en la ley. Se trata, en definitiva, de una sentencia manipulativa de la ley.

\section{CONCLUSIONES}

1. En el caso revisado, la CS confiere flexibilidad a la interpretación del artículo 67 del Código Sanitario. Esta disposición establece con claridad la regla que debe aplicar la Administración (es transitiva), aunque la Corte, validando lo actuado por la SEREMI, la convierte en intransitiva, permitiendo con ello la creación de nueva regulación: una infracción que el legislador no configuró.

2. La CS argumenta que el principio de tipicidad en el Derecho Administrativo sancionador implica la aptitud jurídica para imponer multas en caso de infringirse normas que solo otorgan competencia a una entidad pública. Con ello, sin embargo, flexibiliza a tal medida la vinculación entre la ley y el órgano que, incluso, la rebaja más allá de lo que se aceptaría en cualquier situación ordinaria - esto es, distinta a una sancionatoria- en que la Administración deba intervenir.

3. Pero la Corte tampoco logra entender su propia posición institucional, puesto que las razones que esgrime para justificar el relajamiento de la tipicidad solo tienen lugar tratándose de controlar la dictación de normas -lo que haría el TC en algunos supuesto o la misma CS tratándose, por ejemplo, del recurso de protección en contra de actos administrativos- y no la aplicación de la ley por parte de los órganos administrativos.

4. Una consecuencia de la operación efectuada por la CS en el caso ESSBIO se encuentra en la imposibilidad de que el administrado pueda prever qué se encuentra prohibido $^{57}$ y ajustar su conducta a esa programación, puesto que si cualquier bien o interés jurídico contenido en una norma puede ser infringido por un particular, las hipótesis in-

\footnotetext{
55 DWORKIN $(1977,1978)$ p. 24.

56 Considerando $5^{\circ}$.

57 Dannecker (2013) p. 246.
} 
fraccionales son difíciles de abarcar. Con esto en consideración, es una verdadera contradicción -si no una ironía- que la CS declare en el mismo fallo objeto de este comentario que:

"[1] o que a todo trance debe ser evitado, pues de no ser así se deslegitima la persecución administrativa, es la indeterminación, justamente porque impide al administrado saber a qué atenerse, tanto en lo atinente a lo que vinculantemente debe y no debe hacerse, cuanto en lo que concierne a la consecuencia que de su transgresión puede derivar" 58 .

\section{BIBLIOGRAFÍA CITADA}

Ayres, Ian y Braithwaite, John (1992): Responsive regulation: Transcending the deregulation debate (Oxford, Oxford University Press).

Camacho, Gladys (2006): "La legitimidad de la Potestad Administrativa Sancionadora", Revista de Derecho Público, Vol. 69 No 2: pp. 9-23.

Cordero, Eduardo y AldunAte, Eduardo (2012): "Las bases constitucionales de la potestad sancionadora de la Administración", Revista de Derecho de la Pontificia Universidad Católica de Valparaíso, No 39: pp. 337-361.

Craig, Paul (2007): "Law, Fact and Discretion in the UK, EU and USA", en Sciences-Po/La Chaire Mutations de l'action public et du droit public: pp. 1-34. Disponible en: <http:// www.sciencespo.fr/chaire-madp/sites/sciencespo.fr.chaire-madp/files/paul_craig.pdf>

Dannecker, Gerhard (2013): “Country Analysis-Germany”, en Jansen, Oswald (ed.), Administrative sanctions in the European Union (Cambridge-Antwerp-Portland, Intersentia) pp. 213-254.

DwOrkin, Ronald (1977, 1978): Taking Rights seriously (Cambridge, Harvard University Press).

García de Enterría, Eduardo (1976): "El problema jurídico de las sanciones administrativas", Revista Española de Derecho Administrativo, No 10: pp. 399-430.

García de Enterría, Eduardo y Fernández, Tomás-Ramón (2011): Curso de Derecho Administrativo. II (Navarra, Civitas).

Guiloff, Matías (2012): "Operativizando la relación ley-reglamento: una propuesta de redefinición del rol de la reserva legal", Rev. Derecho (Valdivia) vol. 25, no.1: pp. 127-147.

Habermas, Jürgen (2001): Facticidad y validez. Sobre el derecho y el Estado democrático de derecho en términos de teoría del discurso (Madrid, Trotta).

Huergo, Alejandro (2007): Las sanciones administrativas (Madrid, Iustel).

LONDOÑO, Fernando (2014): "El marco legal administrativo-sancionatorio: hacia una concepción diferenciada de la tipicidad”, en Alarcón, Pablo y Arancibia Mattar, Jaime (eds.), Sanciones Administrativas. X Jornadas de Derecho Administrativo Asociación de Derecho Administrativo (Santiago, Thomson Reuters) pp. 587-605.

58 Considerando $8^{\circ}$. 
Soto Delgado, Pablo " "Un mal caso para flexibilizar la tipicidad en el Derecho Administrativo sancionador ..."

MonTt, Santiago (2010): “Autonomía y responsividad: Dos expresiones de la vocación juridificadora del Derecho Administrativo y sus principios fundamentales”, en Documento de trabajo 4 (Santiago, Centro de Regulación y Competencia Universidad de Chile).

NieTo, Alejandro (2012): Derecho Administrativo sancionador (Madrid, Tecnos).

Nonet y Selznick (2009): Law and society in transition: Toward responsive law (New Brunswick, New Jersey, Transaction Publishers).

Parejo, Luciano (2008): Lecciones de Derecho Administrativo (Valencia, Tirant lo Blanch).

Rubin, Edward L. (2007): Beyond Camelot: rethinking politics and law for the modern state (Princeton, Princeton University Press).

Schmidt-Assmann, Eberhard (2003): La teoría general del Derecho Administrativo como sistema (Madrid, Marcial Pons/INAP)

Schmidt-Assmann, Eberhard (2012): "Cuestiones fundamentales sobre la reforma de la Teoría General del Derecho Administrativo”, en BARNES, Javier (ed.), Innovación y reforma en el derecho administrativo (Sevilla, Global LawPress-Editorial Derecho Global/ Instituto Nacional de Administración Pública).

Vallejo, Rodrigo y Guiloff, Matías (2014): Ni Juez, ni parte: la potestad sancionadora de la administración y la metodología del Derecho Administrativo (en prensa), 48 pp.

Verdugo, Sergio y García, José Francisco (2011): “¿Es la separación de funciones un estándar justiciable para el régimen de sanciones administrativas?”, en DelaVEAU, Rodrigo (ed.) Sentencias Destacadas 2010 (Santiago, Instituto Libertad y Desarrollo) pp. 101131.Disponible en: <http://papers.ssrn.com/sol3/papers.cfm?abstract_id=2084922>

\section{JURISPRUDENCIA CITADA}

Sentencia del Tribunal Constitucional, Rol No 244, de 26 de agosto de 1996.

Sentencia del Tribunal Constitucional, Rol No 480, de 27 de junio de 2006.

Sentencia del Tribunal Constitucional, Rol No 479, de 8 de agosto de 2006.

Sentencia de la Corte Suprema, Rol No 5.779-2009, de fecha 29 de julio de 2011.

Sentencia del 2o Juzgado Civil de Concepción, Rol N³132-2010, de 5 de octubre de 2011.

Sentencia de la Corte de Apelaciones de Concepción, Rol No 86-2012, de 28 de agosto de 2012.

Sentencia de la Corte Suprema, Rol No 7397-2012, de 16 de septiembre de 2013. 